ORIGINAL ARTICLE

AFRICAN JOURNAL OF CLINICAL AND EXPERIMENTAL MICROBIOLOGY $\quad$ MAY $2013 \quad$ ISBN 1595-689X VOL 14(2) 2013

AJCEM/21319

COPYRIGHT 2013

AFR. J. CLN. EXPER. MICROBIOL 14(2): 109-119 http:/ / dx.doi.org/10.4314/ajcem.v14i2.12

\title{
PREVALENCE AND ANTIBIOTIC SUSCEPTIBILITY OF AMPC AND ESBL PRODUCING CLINICAL ISOLATES AT A TERTIARY HEALTH CARE CENTER IN KANO, NORTH- WEST NIGERIA.
}

\author{
*Yusuf, $\mathbf{I}^{1}$., Haruna, $\mathbf{M}^{2}$. and Yahaya, $\mathrm{H}^{3}$ \\ ${ }^{1}$ Department of Microbiology, Faculty of Science, Bayero University, P.M.B 3011, Kano-Nigeria; ${ }^{2}$ Department of Biology, Kano \\ University of Science and Technology, Wudil, Kano, Nigeria; ${ }^{3}$ Department of Medical Laboratory Science, Faculty of Medicine, \\ Bayero University, P.M.B 3011, Kano-Nigeria
}

*Correspondence: E-mail:iyusuf.bio@buk.edu.ng; Phone: +2347037865734

\begin{abstract}
The increase in production of Extended Spectrum Beta Lactamase (ESBL) and Amp C beta lactamase among clinical isolates in our hospitals is of utmost importance. Failure to detect these enzymes in many of our hospitals has greatly led to treatment failure and uncontrolled spread of multi drug resistant pathogens. It was for this purpose that the present study was conducted to determine the prevalence, distribution and susceptibility pattern of Gram negative bacteria producing ESBLs and Amp C beta lactamases in the largest tertiary health care provider in Kano, North-West Nigeria. A total of 75 ESBL and 10 AmpC producing bacteria were involved in the study which were obtained from a study involving 500 Gram negative clinical bacterial isolates from various hospital wards over a period of 9 months from Aminu Kano Teaching Hospital (AKTH), Kano, Nigeria. Isolates were screened for ESBLs and AmpC using Double Disc Diffusion Method and Amp C Disc test respectively. All confirmed ESBL and Amp C producing isolates were tested for susceptibility to sixteen (16) different antibiotics by the Disc Diffusion Method (DDM). The prevalence of ESBLs was high in Shigella spp. (1/2 or 50\%), followed by Klebsiella pneumoniae $(10 / 50$ or $/ 20 \%)$, and E. coli $(47 / 247$ or $19.3 \%)$ while Amp C producers were detected more in Klebsiella pneumoniae (4\%) and E. coli $(2.8 \%)$. Of the specimens screened, distribution varies between ESBL and AmpC producers, but more prevalent in urinary tract pathogens in both. Highest prevalence of ESBLs and AmpC producers was recorded in intensive care units and surgical wards. ESBL and AmpC production in the hospital is not sex dependent statistically, thought higher in males (52 and $60 \%)$ than in females (48 and 40\%) for ESBL and AmpC respectively. ESBL and AmpC producers were both sensitive to Imipenem, Nitrofurantoin and Levofloxacin and resistance to Amoxycillin, Ceftazidime and Tetracycline. The study indicates the occurrence of ESBL and AmpC producers in our tertiary health provider, widely distributed in various clinical samples, wards and sexes and are multi drug resistant posing serious threat in managing life threatening infections.
\end{abstract}

Key words: prevalence, distribution, ESBL producers, Amp C producers, antibiotic susceptibility

\section{INTRODUCTION}

Beta lactamases are enzymes produced by some bacteria and are responsible for their resistance to $B$ lactam antibiotics like penicillins, cephamycin and carbapenem [1]. $\beta$-lactamase deactivates the molecular antibacterial properties of $\beta$-lactam antibiotics there by breaking and opening the common element in their molecular structure $\beta$ lactam. Some of these enzymes include extended spectrum $\beta$-lactamase (ESBL), AmpC $\beta \mathrm{L}$, and carbapenemase. The first $\beta$-lactamase was detected during the 1960s [2]. Since then many types of $\beta$ lactamases which vary both in their ability to inactivate a given beta lactam drug as well as their susceptibility to inhibitors such as clavulanic acid, sulbactam and tazobactam came into existence.

Extended spectrum beta lactamases (ESBLs) are enzymes that mediate resistance to the third generation cephalosporins (e.g ceftazidime, cefotaxime and ceftriaxone) and monobactams (e.g aztreonem) but do not affect cephamycins. The enzymes are now observed worldwide in all species of Enterobacteriaceae especially $K$. pneumoniae and Escherichia coli. Originally, ESBL enzymes were derived from the widespread TEM and SHV $\beta$ lactamase family. The first $\beta$-lactamase with an extended-spectrum was detected in Germany in 1983 
[3] and later in the western parts of Europe, probably because expanded-spectrum $\beta$-lactam antibiotics were first used their clinically.

The Class C $\beta$-lactamases (AmpC) are an important group of proteins that are broadly distributed and are the second most common $\beta$-lactamase group [1]. AmpC $\beta$-lactamases, in contrast to ESBLs, hydrolyse broad and extended-spectrum cephalosporins but are resistant to inhibition by $\beta$-lactamase inhibitors such as clavulanic acid $[4,5,6]$.

In Nigeria, indiscriminate use of antibiotics, poor hygienic practices in hospitals and lack of monitoring of microbial drug resistance have created suitable conditions for the emergency and uncontrollable spread of the ESBLs and Amp C enzymes [7] and thus make their detection complicated due to the variable affinity of these enzymes for different substrates and inoculum effect.

Resistant to commonly used antibiotics in our hospitals increases at an alarming rate. Awareness of their occurrence and their potential effects in managing infectious diseases is low among the health care providers. Laboratory detections of these enzymes, proper reporting, necessary precautions to avoid their spread is lacking in many of our hospitals. In view of this, the research was conducted to detect the prevalence, distribution and antibiotic susceptibility of ESBL and AmpC producing clinical isolates in a tertiary health care provider which serves as a referral centers for other hospital in the region.

\section{MATERIALS AND METHODS}

\section{Collection of specimens}

A total of eighty five (85) Gram negative bacterial isolates comprising of $75 \mathrm{ESBL}$ and $10 \mathrm{AmpC}$ producing isolates were involved in the study. The screening was done in a study involving 500 clinical isolates collected from various clinical samples and hospital wards of the Microbiology Department of Aminu Kano Teaching Hospital (AKTH), Kano, Nigeria. The isolates were identified according to the procedures described by Cheesbrough [8]. Ethical clearance was granted to conduct the research by the management of the hospital.

\section{Presumptive Test for ESBLs}

All the clinical isolates collected were tested for potential ESBL producers using the Cefpodoxime $(10 \mu \mathrm{g})$ and the Ceftriaxone $(30 \mu \mathrm{g})$ antibiotic discs. Results were interpreted based on the CLSI criteria [9].

\section{Confirmatory Test for ESBLs}

All isolates suspected of ESBL production in the presumptive test were furthered confirmed using the double discs synergy according to CLSI guidelines [9]. A suspension of the test organism was inoculated on Mueller- Hinton agar. A disc containing 30 $\mu \mathrm{g}$ Amoxicillin plus clavulanic acid was placed centrally on the plate. Discs containing cefpodoxime $(10 \mu \mathrm{g})$ and ceftriaxone $(30 \mu \mathrm{g})$ were placed on the agar at a distance of $15 \mathrm{~mm}$, centre to centre away from the amoxicillin + clavulanic acid disk. The plates were incubated over night at $35^{\circ} \mathrm{C}$. The results were then interpreted as outlined in the CLSI guidelines [9]. A $\geq$ $5-\mathrm{mm}$ increase in zone diameter for either antimicrobial agent combination compared to its zone when tested alone signified a positive ESBL.

\section{PRESUMPTION TEST FOR Amp C}

Sensitivity cefoxitin $(30 \mu \mathrm{g})$ discs were used to test for Amp C production using the disc diffusion method and interpreted as per the CLSI criteria [9]. Isolates that yielded a zone diameter less than $18 \mathrm{~mm}$ (screen positive) were further subjected to confirmatory test using the AmpC disc test technique.

\section{AMP C DISK TEST}

All confirmed isolates from the presumptive test were then subjected to the Amp C disc test as described by black et al [10]. A lawn culture of E. coli ATCC 25922 was prepared on MHA plate. Sterile disks $(6 \mathrm{~mm})$ were moistened with sterile saline $(20 \mu \mathrm{l})$ and inoculated with several colonies of test organism. The inoculated disk was then placed beside a cefoxitin disk (almost touching) on the inoculated plate. The plates were incubated overnight at $35^{\circ} \mathrm{C}$. A positive test appeared as a flattening or indentation of the cefoxitin inhibition zone in the vicinity of the test disk. A negative test had an undistorted zone. 


\section{ANTIMICROBIAL SUSCEPTIBILITY TESTING}

Antibiotic susceptibility tests were performed on all the confirmed ESBLS and Amp C Beta lactamase positive isolates according to CLSI directives [9]. The results were expressed as susceptible or resistant according to criteria developed by CLSI [9]. Sixteen (16) different antibiotic discs (Oxoid) were used : Gentamicin $(10 \mu \mathrm{g}), \quad$ Cotrimoxazole $(25 \mu \mathrm{g})$, Ciprofloxacin $(5 \mu \mathrm{g}), \quad$ Cefpodoxime $(30 \mu \mathrm{g})$, Ceftazidime $(30 \mu \mathrm{g})$, Ceftriaxone $(30 \mu \mathrm{g})$, Cefoxitin $(30 \mu \mathrm{g})$, Imipenem $(10 \mu \mathrm{g})$ Nalidixic Acid $(30 \mu \mathrm{g})$, Amoxycillin $(20 \mu \mathrm{g})$, Ofloxacin $(30 \mu \mathrm{g})$, Levofloxacin $(30 \mu \mathrm{g})$, Nitrofurantoin $(300 \mu \mathrm{g})$, Tetracycline $(30 \mu \mathrm{g})$,

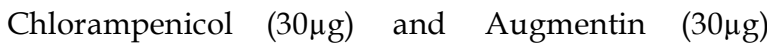
(Oxoid). Escherichia coli ATCC 25922 strain was used as a control culture.

\section{RESULTS}

\section{ESBL Producing Isolates}

Out of the 500 isolates screened for ESBL production, 75 were confirmed to produce ESBL giving an overall prevalence of $15.0 \%$. The highest prevalence of ESBLs was found in Shigella spp $(1 / 2$ or $50 \%)$ followed by Klebsiella pneumoniae $(10 / 50$ or $20.0 \%)$, E. coli $(47 / 247$ or $19.3 \%)$, Salmonella spp $(2 / 12.5 \%)$ and Proteus mirabilis (14/11.8\%) (Table1).

TABLE 1: PREVALENCE OF ESBL PRODUCERS AT ATKH, KANO.

\begin{tabular}{|l|c|c|c|}
\hline \multicolumn{1}{|c|}{ Isolates } & No. screened & No. of confirmed ESBLs & \% confirmed ESBLs \\
\hline E. coli & 247 & 47 & 19.3 \\
\hline P. mirabilis & 119 & 14 & 11.8 \\
\hline K. pneumonia & 50 & 10 & 20 \\
\hline Ps. Aeruginosa & 66 & 1 & 1.5 \\
\hline Salmonella spp. & 16 & 2 & 12.5 \\
\hline Shigella spp. & 2 & 1 & 50 \\
\hline Total & 500 & 75 & 15 \\
\hline
\end{tabular}

Plasmid mediated AmpC producing Isolates

The overall prevalence of AmpC $\beta$-lactamases was $10 \%$. Highest prevalence was found among $K$. pneumoniae $(2 / 4.0 \%)$, followed in that order by E. coli
$(7 / 2.8 \%)$ and $P . \quad$ mirabilis $(1 / 0.8 \%)$. Amp C Beta lactamases were not detected among Shigella spp., Salmonella spp. and Ps. aeruginosa isolates (Table 2).

TABLE 2: PREVALENCE OF AMP C BETA LACTAMASE PRODUCERS AT AKTH, KANO.

\begin{tabular}{|l|c|c|c|}
\hline Isolates & No. screened & No. of confirmed Amp C & \% confirmed Amp C \\
\hline E. coli & 247 & 7 & 2.8 \\
\hline P. mirabilis & 119 & 1 & 0.8 \\
\hline K. pneumonia & 50 & 2 & 4.0 \\
\hline Ps. Aeruginosa & 66 & 0 & 0.0 \\
\hline Salmonella spp. & 16 & 0 & 0.0 \\
\hline Shigella spp. & 2 & 0 & 0.0 \\
\hline Total & 500 & 10 & 2.0 \\
\hline
\end{tabular}

\section{Distributions of $\beta$-lactamases}

The distribution of ESBL and AmpC producers in clinical samples, clinics/wards and sexes were presented in Table 3, 4 and 5 respectively. ESBL producers were most prevalent in blood (14/22.2\%) and urine samples $(48 / 17.6 \%)$. This was followed in that order by stool $(3 / 15.8 \%)$, urogenital swabs $(1 / 14.3 \%)$ and wound swab (5/13.5\%) while the least prevalence was observed in ear swab specimens $(2 / 3.2 \%)$ (Table 3). However, AmpC was more prevalent in urine and catheter tips.

\section{Antimicrobial Susceptibility Testing}

Antimicrobial susceptibility of ESBL producers to the selected antibiotics showed that both the ESBL and AmpC producing isolates showed appreciable susceptibility to carbapenem (Imipenem) and flouroquinolones (Lev, Cip, Nit and Nal). E. coli producing ESBLs are more susceptible to IMI (40/47), followed by LEV (32/47), Nal (30/47), NIT (26/47) and OFL (25/47). Resistance to penicillin and $2^{\text {nd }}$ and $3^{\text {rd }}$ generation cephalosporin were high but total in CAZ, CHL and TET. However, ESBL producing $K$. pneumoniae showed more resistance to more 
TABLE 3: DISTRIBUTION OF ESBL AND AMPC PRODUCERS AMONG CLINICAL SPECIMENS AT AKTH, KANO

\begin{tabular}{lll}
\hline Samples & No. and \% of ESBLs & No and \% of AmpC \\
\hline Ear Swab & $2(3.2)$ & $1(10)$ \\
Urine & $48(17.6)$ & $5(50.0)$ \\
Catheter Tip & $2(8.7)$ & $2(20.0)$ \\
wound Swab & $5(13.5)$ & $0(0)$ \\
Blood & $14(22.2)$ & $1(10)$ \\
Stool & $3(15.8)$ & $0(0)$ \\
Urogenital Swab & $1(14.3)$ & $1(10)$ \\
Total & 75 & 10 \\
\hline
\end{tabular}

The highest prevalence of ESBLs from the various clinical sections/units at the AKTH, Kano was recorded at the nephrology, dialysis and surgical outpatient units $(100 \%)$ while Ear, Nose and Throat clinic (5.6\%) had the least prevalence (Table 4). AmpC producers also showed similar pattern of ESBL with highest prevalence in ICU, SCBU, MSW and SOPD. The distribution of ESBL and AmpC producers based on gender indicates that males had a higher prevalence rate $(37 / 15.3 \%)$ than females $(38 / 14.7 \%)$ (Table 5).

Moreover, Ps. aeruginosa and K. pneumoniae also showed same pattern of susceptibility profile with more susceptibility to carbapenem and flouroquinolones (fig $2 \& 3$ ) and total resistance to AMX, AUG, CTR, CAZ, CHL and TET. 
TABLE 4: DISTRIBUTION OF ESBL AND AMPC PRODUCERS AMONG CLINICAL SECTIONS/UNITS AT ATKH, KANO.

\begin{tabular}{|c|c|c|c|c|c|c|}
\hline \multirow{2}{*}{$\begin{array}{l}\text { Clinical wards } \\
\text { GOPD }\end{array}$} & \multirow{2}{*}{\begin{tabular}{|l} 
No. \\
168
\end{tabular}} & \multicolumn{2}{|c|}{ No. and $\%$ of ESBLs SOPD } & \multicolumn{2}{|c|}{ No. and $\%$ AmpC } & \multirow{2}{*}{$\begin{array}{l}3(100) \\
1(25.0)\end{array}$} \\
\hline & & 22(13.1) & FSSW & $1(0.6)$ & 4 & \\
\hline POPD & 53 & $4(7.5)$ & EPU & $0(0.0)$ & 30 & $3(10.0)$ \\
\hline$A \& E$ & 29 & $3(10.3)$ & PMW & $0(0.0)$ & 15 & $6(40.0)$ \\
\hline ENT & 18 & $1(5.6)$ & ANC & $0(0.0)$ & 11 & $3(27.3)$ \\
\hline MMW & 24 & $7(29.2)$ & OPD & $0(0.0)$ & 5 & $1(20.0)$ \\
\hline MOPD & 8 & $2(25.0)$ & PNW & $0(0.0)$ & 5 & $1(20.0)$ \\
\hline SCBU & 20 & $6(30.0)$ & NEPHROLOGY & $2(10)$ & 1 & $1(100.0)$ \\
\hline FMW & 18 & $5(27.8)$ & DIALYSIS & $0(0.0)$ & 1 & $1(100.0)$ \\
\hline NEOCLINIC & 2 & $1(50.0)$ & ICU & $0(0.0)$ & 2 & $1(50.0)$ \\
\hline MSW & 12 & 216.7) & Total & $3(40.0)$ & 441 & $75(17.0)$ \\
\hline RETAINERSHIP & 12 & $1(8.3)$ & 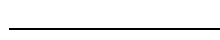 & $0(0.0)$ & & \\
\hline
\end{tabular}


TABLE 5: GENDER BASED PREVALENCE OF ESBL AND AMPC PRODUCERS AT AKTH, KANO.

\begin{tabular}{lll} 
Sex & No. \& \% confirmed ESBLs & No. \& \% confirmed AmpC \\
\hline Male & $39(52)$ & $6(60)$ \\
Female & $36(48)$ & $4(40)$ \\
\hline
\end{tabular}

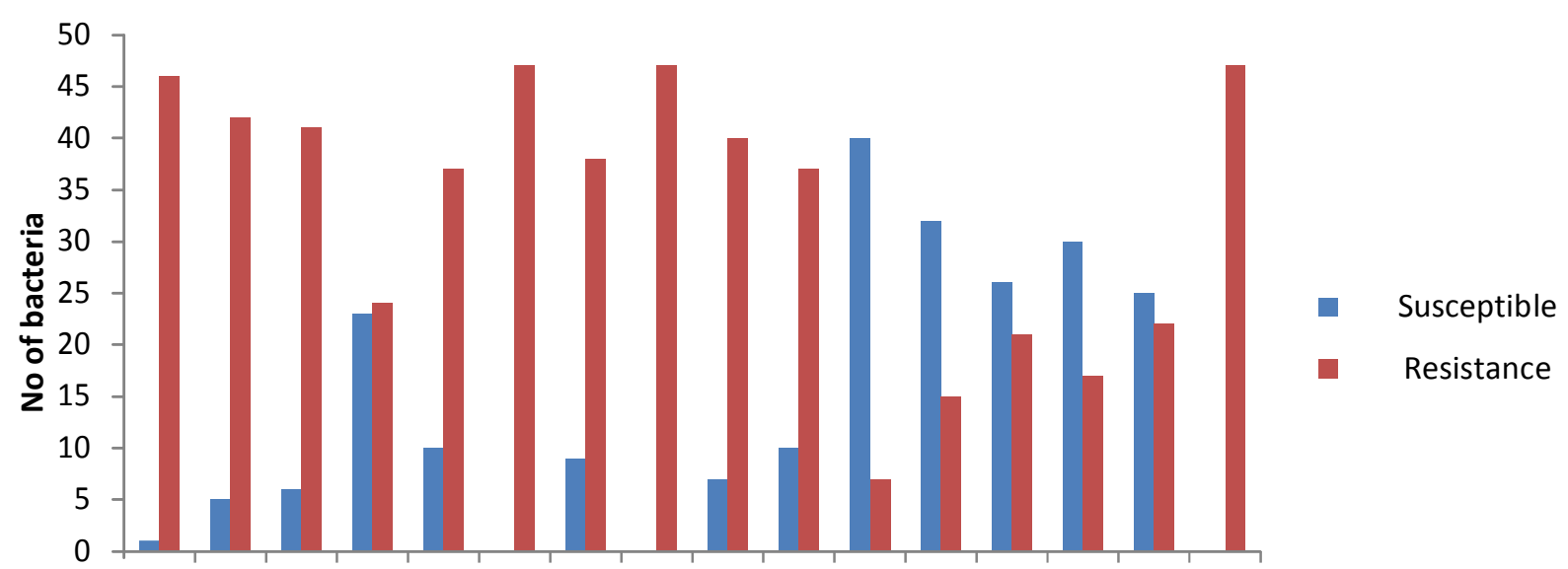

AMXAUG FOX CPM CTR CAZ CIP CHL COT GEN IMI LEV NIT NAL OFL TET

Fig1. Antibiotic susceptibility profile of 47 ESBL producing E. coli to commonly used antibiotics in a tertiary health care in Kano, North West Nigeria

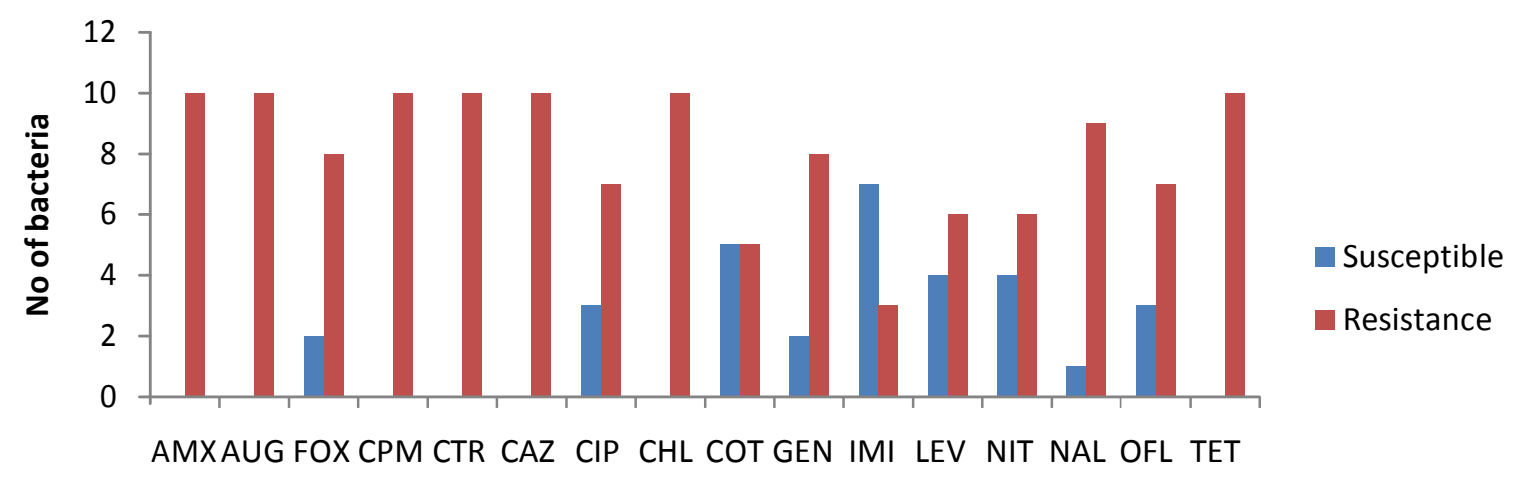

Antibiotics

Fig 2. Antibiotic susceptibility profile of ESBL producing K. pneumoniae to commonly used antibiotics in a tertiary health care in Kano, North West Nigeria 


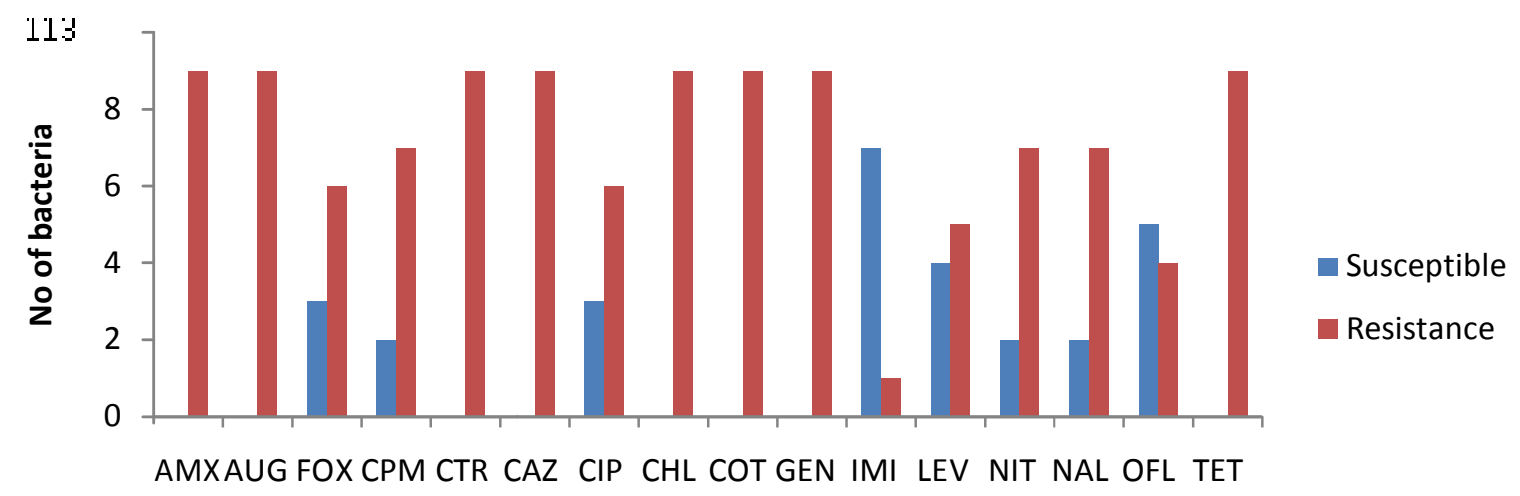

Antibiotics

Fig 3: Antibiotic susceptibility profile of ESBL producing $P$. aeruginos $a$ to commonly used antibiotics in a tertiary health care in Kano, North West Nigeria

While AmpC producing E. coli are sensitive to IMI, LEV, CIP, NAL, and OFL (fig 4), AmpC producing K. pneumoniae are more sensitive to LEV, OFL, GEN and IMI (fig 5). Most of the K. pneumoniae are resistant to majority of the tested.

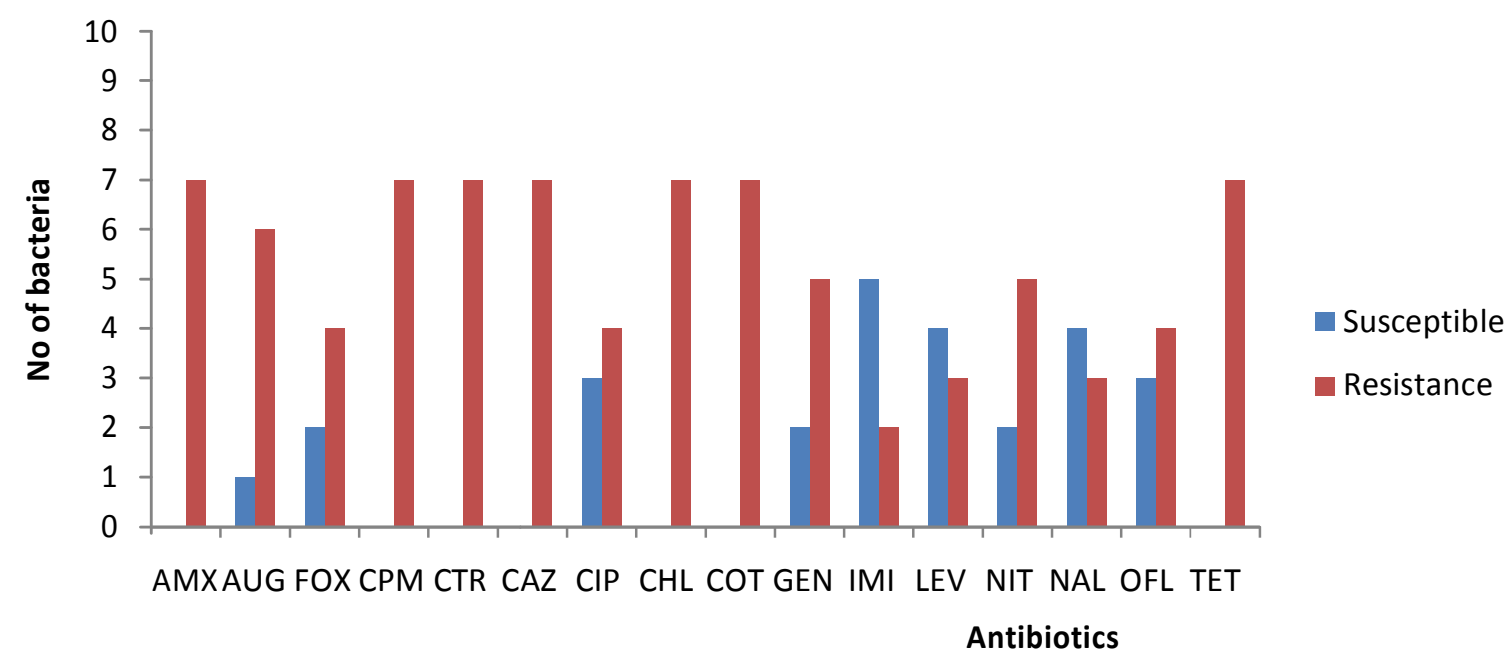

Fig 4: Antibiotic susceptibility profile of AmpC producing E. coli to commonly used antibiotics in a tertiary health care in Kano, North West Nigeria 


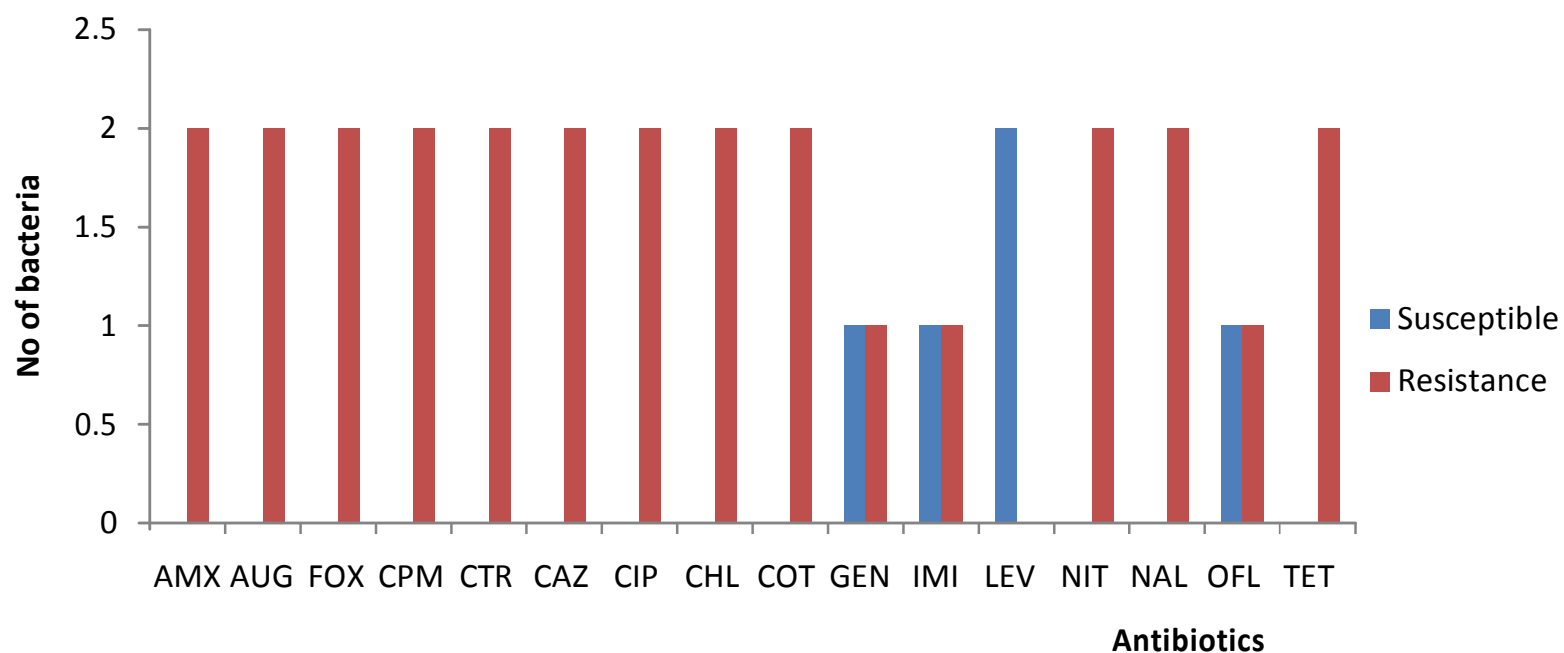

Fig 5. Antibiotic susceptibility profile of AmpC producing K. pneumoniae to commonly used antibiotics in a tertiary health care in Kano, North West Nigeria

\section{DISCUSSION}

Multi drug-resistant (MDR) Gram negative bacilli induced infections have been reported with an increasing frequency in tertiary health care providers in Nigeria and they have been found to be associated with a significant morbidity and mortality [11]. The numerous $\beta$ - lactamases such as ESBL and AmpC were encoded either by the chromosomal genes or by the transferable genes which are located on the plasmids or the transposones [12]. The overall prevalence of ESBL and AmpC producers in this study was $15 \%$ and $10 \%$ respectively (table 1,2). Although an increase in ESBL production have been reported in previous studies [13, 14], our results showed comparatively higher overall levels of ESBLand AmpC producers. Among the Gram negative bacteria screened for ESBL production, Shigella spp. had the highest prevalence $(50 \%)$. This could be attributed to the fact that the bacterium has been progressively acquiring resistance to several antimicrobial agents used for the treatment of infections [15]. Although the number of the isolates recovered during the study was 2 , but several reports have indicated an increase in cases of Shigella species resistant to beta-lactams, including third-generation cephalosporins [15].

Comparison of the prevalence rate of ESBLs (15\%) found in this study with findings of similar studies from same state indicated that the prevalence rate in the present study is higher when compared to previous studies by Yusha'u et al. [14, 16] who reported prevalence of $9.25 \%$ and $10.31 \%$ in 2007 and 2009 respectively, but lower to reports from other parts of the country, such as Lagos, $20 \%$ [17], Benin $36.6 \%$ and Enugu $44.6 \%$ [18]. This variations could be due to the differences in selecting type of antibiotic, antibiotic selection pressure, local antibiotic and prescribing habits, which differ from state to state, country to country and from institution to institution.

Among the clinical specimens, blood (22.2\%) had the highest prevalence of ESBL producers followed by urine $(17.6 \%)$. This observation is in agreement with that of Osazuwa et al. [18] who found that ESBL prevalence was highest for blood (61.2\%) and urine $(16.41 \%)$ specimens. This might be attributed to factors like improper use of syringes or needles, inadequate disinfection of skin of prolonged hospital stayed patients during phlebotomy or transfusion, poor hand washing techniques among health care practitioners which are some of the factors that predispose one to blood stream infections.

The distribution of ESBLs and AmpCs in hospital sections/units was highest in the nephrology, dialysis, surgical outpatient wards (100\%) followed in that order by the ICU and the SCBU $(50 \%)$. This indicates that they are more found among the hospitalized patients who may have contact them in 
the hospital or from the health care providers. Some of these units mostly deal with seriously ill patients with life threatening infections and those in need of special postoperative techniques and are placed on prolonged antibiotic therapy. High prevalence of ESBL and AmpC in ICUs in the hospital has negative health implications, and could result into prolonged hospital stay, increased cost of treatment and quick spread in the hospital setting. Major risk factors for colonization or infection with ESBL and AmpC producing organisms are long term antibiotic exposure, prolonged ICU stay, nursing home residency, severe illness, residence in an institution with high rates of third generation cephalosporin use and instrumentation or catheterization [19]. AKTH being a tertiary care that served as referral center for other hospitals within and outside the metropolis, it received many patients from various government owned and private owned hospitals with varying complicated life threatening infections. This has lead to use of higher antibiotics by the clinicians as a common empirical therapy without screening for ESBL and or AmpC. In addition, due to heavy patients load from other hospitals, proper infection control measures cannot be maintained by the paramedical staffs which can lead to transfer of MDR to other hospital. All of these factors lead to the higher rate of ESBL and AmpC $\beta$-lactamase producing organisms in our institution.

Based on gender, the distribution of the duo was not statistically significant as prevalence of 52 and $48.7 \%$ was recorded for ESBLs while $60 \%$ and $40 \%$ was recorded for AmpC beta lactamase $(\mathrm{P}<0.05)$. However, in another study, Erum et al. [20] reported increased ESBL production in males as compared to females. It was hypothesized that males in general have more obstructive uropathies leading to frequent urinary catheterization and have more chronic pulmonary and cardiovascular diseases that in turn lead to increased hospitalization and higher prevalence.

The distribution of antibiotic resistance to B-lactams in this study was very similar to that described by Stéphane et al. [21] with nearly all of the isolates being resistant or slightly susceptible to commonly prescribed antibiotics in the hospitals, and many of the isolates showing a decreased susceptibility or resistance to promising antibiotics such as imipenem, levofloxaxin, cefoxitin, cefpodoxime and ceftriaxone (fig 1). The study showed that imipenem and levofloxacin were still the most effective antibiotics against ESBL and Amp C beta lactamase producing bacteria. However, data showed that imipenem usage in the hospital is low when compared with levofloxacin. Thus, these drugs could be used to treat infections caused by bacteria capable of producing these enzymes especially in cases of life-threatening infections such as urinary tract infections and pulmonary pneumonia. However, unless antibiotic therapy is restricted and controlled legally, misuse in the form of self medication may cause the spread of resistance, which will result in the prevalence of resistance against effective antibiotics such as levofloxacin and carbapenems

\section{CONCLUSION}

Based on the findings of this study, it could be deduced that:

- Prevalence of ESBL and AmpC Betalactamases producing gram negative bacteria is on the increase in a tertiary health care in Kano North West Nigeria.

- Blood and urine samples had a higher prevalence of ESBL producers in Kano

- The resistant pathogens were more found Neurology, dialysis and surgical out patient clinical sections/ units in addition to intensive care units.

- Prevalence of ESBL and AmpC producing bacteria does not differ significantly between the sexes.

- Levofloxacin and Imipenem is choice antibiotic for the treatment of infections caused by ESBL and Amp C producing bacteria in the hospital.

\section{ACKNOWLEDMENTS}

We are indebted to Dr Nasiru Magaji of the Microbiology Department, Aminu Kano Teaching Hospital, Kano for providing the control strain and logistics for the smooth conduct of the research. We also wish to thank other medical laboratory scientists and clinicians of Aminu Kano Teaching Hospital, Kano for their contributions in provision and save keeping of the clinical isolates for the study. 


\section{REFERENCES}

1. Bush, K., Jacoby, G. A. and Medeiros, A. A. (1995). A Functional Classification Scheme for $\beta$ lactamases and its Correlation with Molecular Structure. Antimicrob. Agents Chemother. 39:1211-33.

2. Datta, N. and Kontomichalou, P. (1965)."Penicillinase synthesis controlled by infectious R factors in Enterobacteriaceae." Nature 208: 239-41.

3. Kliebe, C., Nies, B.A., Meyer, J.F., TolxdorffNeutzling, R.M., and Wiedemann, B. (1985). "Evolution of plasmid-encoded resistance to broad-spectrum cephalosporins." Antimicrob Agents Chemother 28: 302-7.

4. Sanders, C.C. (1987)."Chromosomal Cephalosporinases Responsible for Multiple Resistance to Newer beta -Lactam Antibiotics." Annu Rev Microbiol 41: 573-594.

5. Thomson, K.S. (2001). Controversies about Extended- Spectrum and AmpC Blactamases. Emerg Infect Dis 7:333-6.

6. Hanson, N.D. (2003). AmpC beta-lactamases: what do we need to know for the future? J Antimicrob Chemother. 52:2-4.

7. Arzai, A.H. and Adamu, D.J.M. (2008). Prevalence of beta-lactamase Producers among randomly selected bacterial pathogens in Kano, Nigeria. Biological and Environmental Sciences Journal for the Tropics 5 (3):218-223.

8. Cheesbrough, M. (2005). District Laboratory Practice for Tropical Countries (Part 2). Cambridge University Press. Pp. 180-197.

9. Clinical Laboratory Standards Institute (CLSI) (2005). Performance standards for antimicrobial disk susceptibility test. 8th ed. Approved standards, M2-A8, Wayne, Pa (USA).

10. Black, J. A., Moland, E.S. and Thomson, K.S. (2005). AmpC disk test for detection of plasmid-mediated AmpC $\beta$-lactamases in Enterobacteriaceae lacking chromosomal
AmpC $\beta$-lactamases. J. Clin. Microbiol. 43:3110-3113

11. Yusuf, I., Yusha'u, M., Sharif, A.A., Getso, M.I., Yahaya, H., Bala, J.A., Aliyu, I.A. and Haruna, M. (2012). Detection of Metallo betalactamases among Gram negative bacterial isolates from Murtala Muhammad Specialist Hospital, Kano and Almadina Hospital Kaduna, Nigeria. Bayero Journal of Pure and Applied Sciences 5(2): 84-88

12. Mary, V.J., Kandathi, A.J, Balaji, V. (2005). Comparison of the methods for the detection of the carbapenamase and the metallo- $\beta$ lactamases production in the clinical isolates. Ind. J. Med. Res.121:780-83.

13. Yusuf, I., Arzai, A.H., Umar, A., Magaji, N., Salisu, N., Tukur, A. and Haruna, M. (2011). Prevalence of Extended Spectrum BLactamases (ESBL) producing Escherichia coli and Klebsiella pneumoniae in Tuberculosis patients in Kano, Nigeria. Bayero Journal of Pure and Applied Sciences. 4(2):182-185.

14. Yusha'u, M., Olonitola, S.O. and Aliyu, B.S. (2009). Prevalence of Extended-Spectrum Blactamases (ESBLS)producing enterobacteriaceae in Kano, Nigeria. International Journal of Biomedical and Health Sciences. 5(2): 79-86.

15. Ahmad, H.S., George, F.A., Mireille, M.K., Roland,Y.A., Marie, T.K., John, D.K., and Ghassan, M.M. (2009). Molecular characterization of ESBL-producing Shigella sonnei isolates from patients with bacilliary dysentery in Lebanon. J Infect .Dev. Ctries 3(4): 300- 05.

16. Yusha'u, M., Olonitola, S.O. and Aliyu, B.S. (2007). Prevalence of Extended-spectrum BLactamases (ESBLs) Among Member of the Enterobacteriaceae Isolates obtained From Muhammad Abdullahi Wase Specialist Hospital, Kano, Nigeria .Int. J. P. App. Scs., 1(3): $42-48$

17. Aibinu, I.E., Ohaegbulam,V.C., Adenipekun, E.A., Ogunsola, F.T., Odugbemi, T.O., Mee, B. J. (2003). Extended-Spectrum $\quad \beta$-Lactamase Enzymes in Clinical Isolates of Enterobacter species from Lagos, Nigeria. J Clin Microbiol. 41(5): 2197-2200. 
18. Osazuwa, F. and Osazuwa, E.O. (2011). Detection of extended spectrum beta-lactamase producing Klebsiella pneumoniae and their susceptibility rates to antibiotics in University of Benin Teaching Hospital, Benin City, Nigeria. Research Journal of Pharmaceutical, Biological and Chemical Sciences (RJPBCS ). 2(1):603 -05.

19. Chaudhary, U., Aggarwal, R. (2004). Extended spectrum - lactamases (ESBL) - An emerging threat to clinical therapeutics. Indian J Med Microbiol. 22:75-80.
20. Erum, K., Muslima, E., Afia, Z., Kauser, J., Sadia, S., Raunaq, I., and Rumina, H. (2010). Increased isolation of ESBL producing Klebsiella pneumoniae with emergence of carbapenem resistant isolates in Pakistan: Report from a tertiary care hospital. J Pak Med Assoc. 60(3):186-190.

21. Stéphane, C., Nathalie, C., Eric, E., Cécile, G., Henri, D. and Alain, R. (2003). AmpC cephalosporinase hyperproduction in Acinetobacter baumannii clinical strains. J. Antimicrob. Chemother. 52 (4): 629-635. 